\title{
PREVISÃO DE CONSUMO DE ENERGIA UTILIZANDO REDE NEURAL COM RETARDO DE TEMPO (TDNN)
}

\section{FORECASTING ENERGY CONSUMPTION USING TIME DELAY NEURAL NETWORK (TDNN)}

Bruno Parpinelli Bonfim, Rafael Bratifich, Marcelo Marques da Silva, Hugo Gomes Silva

Universidade do Oeste Paulista - UNOESTE, Presidente Prudente, SP.

E-mail: bruno parpinelli@hotmail.com

RESUMO - As redes neurais artificiais (RNA), são modelos computacionais inspiradas na forma de trabalho do sistema nervoso dos seres vivos, esses modelos podem ser utilizados para processamento e classificação de dados e aplicações, tais como previsão de séries e funções. Dessa forma, neste trabalho utilizou-se uma rede neural com retardo de tempo (TDNN) para prever a demanda de energia ativa no barramento P4 na cidade de Presidente Prudente.

Palavras-chave: Redes neurais artificiais; modelos computacionais; classificação de dados.

\begin{abstract}
As artificial neural networks (ANN), they are computational models inspired by the way the nervous system of living beings work, these models can be used for processing and classification of data and applications, such as series and function prediction. Thus, this work used a time-delayed neural network (TDNN) to predict the demand for active energy on the P4 bus in the city of Presidente Prudente.
\end{abstract}

Keywords: Artificial neural networks; computational models; data classification.

\section{INTRODUÇÃO}

Algoritmos genéticos, otimização por enxame de partículas e redes neurais artificiais, são frutos da inteligência computacional, e muitas são suas aplicações, como por exemplo: a estimação de observadores inteligentes, identificação de padrões, classificação de imagens clínicas, reconhecimento facial, previsão de séries e funções e entre outras. (SIQUEIRABATISTA et al., 2014).

As Redes Neurais Artificiais (RNA), são modelos computacionais inspirados intrinsecamente no comportamento biológico dos sistemas nervosos dos seres vivos. São formadas por um conjunto de unidades simples de processamento, caracterizando os neurônios artificiais, os quais são interligados entre si para troca de informações (sinapses artificiais). (SILVA; SPATTI; FLAUZINO, 2010).

\section{NEURÔNIO}

A base para o processamento das informações no sistema nervoso do ser humano, é o neurônio. Está célula é responsável pela produção de impulsos nervosos, que são transmitidos através de uma grande rede neural no organismo. A figura 1 demonstra uma 
ilustração do neurônio encontrado no sistema nervoso humano. (BERCl, 2008).

Figura 1. Neurônio humano.

Dendritos

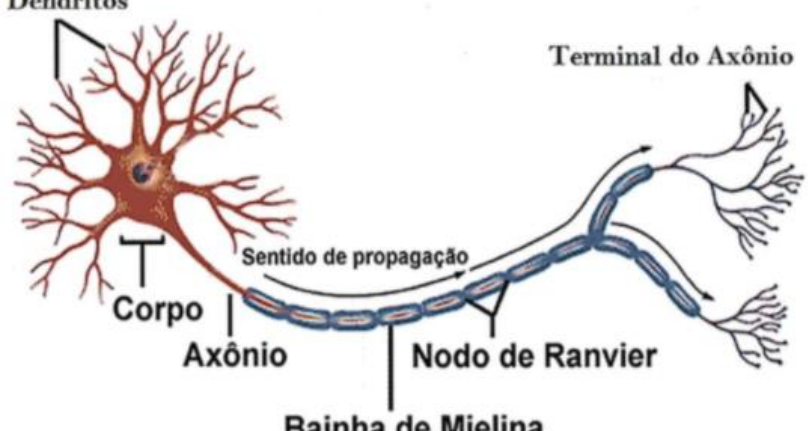

Bainha de Mielina

Fonte: (BEAR; CONNORS; PARADISO, 2008).

As funções/definições simples de cada parte do neurônio acima mencionada são as seguintes:

1. Bainha de Mielina: sua principal função é manter o isolamento do sinal elétrico a ser transmitido;

2. Terminal do Axônio: realiza o transporte dos sinais elétricos para outros neurônios, ou para outros tecidos;

3. Corpo: é o núcleo do neurônio, composto por material genético;

4. Dendritos: são prolongamentos, que recebem sinais elétricos de outros neurônios, ou de outros tecidos.

O processamento da informação no neurônio é realizado através de sinais (impulsos elétricos) trocados entre o dendrito e o terminal axônio dos neurônios. Estes impulsos são responsáveis pela alteração da diferença de potencial elétrico intracelular e extracelular. Isso acontece quando a célula nervosa é estimulada (despolarizada) através de um limiar de ativação $(-55 \mathrm{mV})$, que é ocasionado pela variação da concentração de íons de sódio $\left(\mathrm{Na}^{+}\right)$e potássio $\left(\mathrm{K}^{+}\right)$em seu núcleo. (SILVA; SPATTI; FLAUZINO, 2010). Quando ativado, o neurônio passa o impulso elétrico para os outros neurônios, ou tecidos.
Figura 2. Limiar de ativação do neurônio.

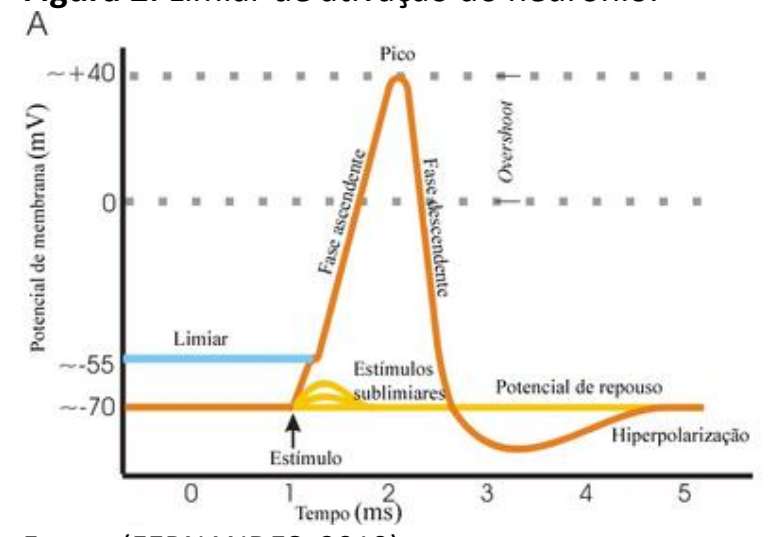

Fonte: (FERNANDES, 2019).

\subsection{Redes neurais artificias}

As redes neurais artificias foram desenvolvidas a partir de modelos conhecidos dos sistemas nervosos biológicos. O modelo mais simples que engloba as características biológicas, foi proposto por McCulloch \& Pitts Perceptron (MCP) em 1943, sendo ainda hoje o modelo mais utilizado nas diversas arquiteturas de RNA.

Este modelo matemático é representado por $n$ entradas representando os dendritos $\mathrm{e}$ uma saída representado o axônio. A saída deste neurônio possuí os dois estados biológicos, ativo e inativo.

Figura 3. Neurônio proposto por McCulloch e Pitts.

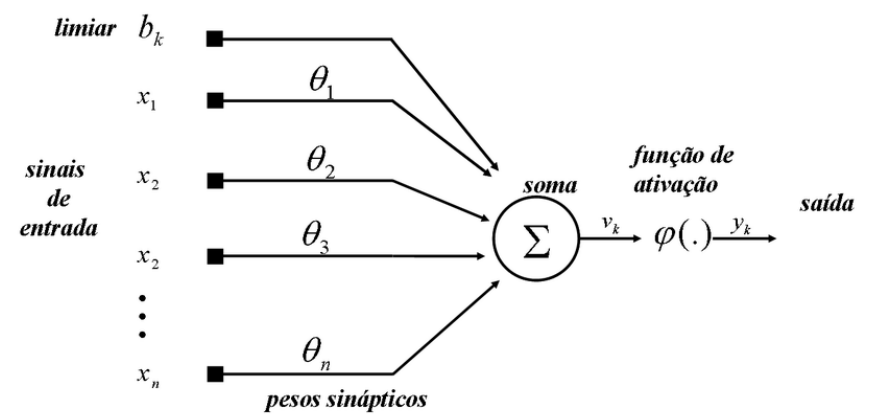

Fonte: (FURTADO; CAMPOS; MACAU, 2011).

As entradas $x_{1}, x_{2}, x_{3}, \ldots, x_{n}$, são multiplicadas pelos valores escalares $\theta_{1}, \theta_{2}, \theta_{3}, \ldots, \theta_{n}$, que representam os pesos sinápticos, ponderando-se, portanto, as informações externas que chegam ao neurônio.

O potencial de ativação $\left(v_{K}\right)$, é o resultado produzido pela diferença entre o combinador linear $\sum_{i=1}^{n} x_{i} \theta_{i}$ e um valor do limiar de ativação $\left(b_{k}\right)$. Se $v_{k} \geq b_{k}$ então o neurônio produz um potencial excitatório, caso contrário, o potencial será inibitório.

$$
\begin{aligned}
& v_{k}=x_{i} \theta_{i}-b_{k} \\
& y_{k}=\varphi\left(v_{k}\right)
\end{aligned}
$$


onde $\varphi\left(v_{k}\right)$ é a função de ativação e $y_{\mathrm{k}}$ a saída do neurônio.

A função de ativação tem o objetivo de limitar a saída do neurônio, uma vez que a soma das entradas não é limitada. Resumindo todo o funcionamento do neurônio artificial, segue os seguintes passos do processo de tratamento da informação de entrada:

1. Inserção de um conjunto de valores que representam as entradas do neurônio;

2. Multiplicação de cada entrada por seu respectivo peso sináptico;

3. Obtenção do potencial de ativação, produzida pela diferença do limiar de ativação e o combinador linear;

4. Aplicação de uma função de ativação apropriada, a fim de limitar a saída do neurônio;

5. Compilação das saídas através do uso da função de ativação em relação ao seu potencial de ativação.

\subsection{Função de ativação}

Com relação às funções de ativação, existem dois principais grupos: as funções parcialmente diferenciáveis e as funções totalmente diferenciáveis. Para este segundo grupo de funções, uma de suas aplicações é a previsão e aproximação de séries e funções, justamente a aplicação trabalhada neste artigo. (ARANTES, et al, 2016).

\subsubsection{Funções totalmente diferenciáveis}

As funções totalmente diferenciáveis, são àquelas que possuem todos os pontos de seu domínio definidos para as derivadas de primeira ordem. Neste grupo, se destacam: a função logística, função tangente hiperbólica e a função linear. (MACHADO; FONSECA JÚNIOR, 2013).

a) Função logística: pertence à classe de funções sigmoidais, ou seja, tem sua forma em " $\mathrm{S}$ ". O resultado de saída produzido por sua aplicação, sempre assumirá valores reais entre zero e um, sua expressão é descrita a baixo:

$$
\phi\left(v_{k}\right)=\frac{1}{1+\mathrm{e}^{-\beta . v_{k}}}
$$

onde $\beta$ é uma constante real associada ao grau de inclinação da função logística face ao ponto de inflexão.
Figura 4. Função de ativação logística.

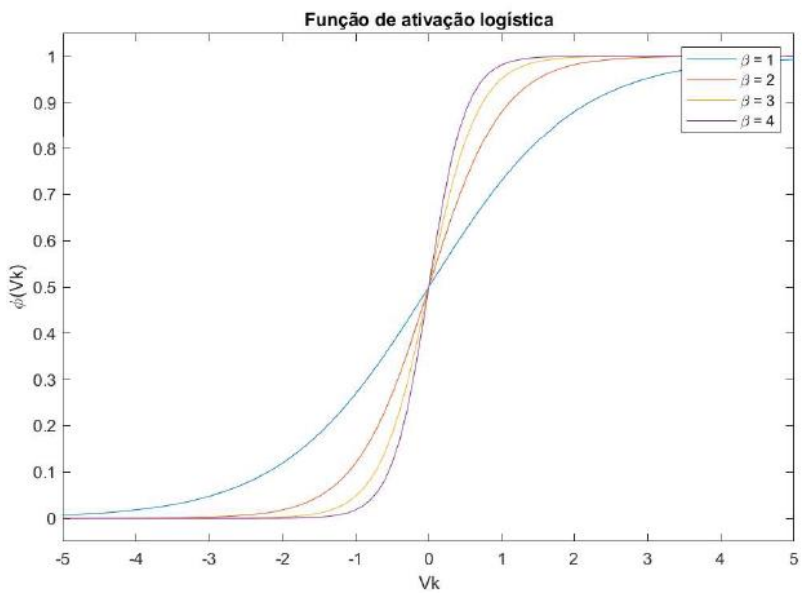

Fonte: Os autores.

b) Função tangente hiperbólica: a função tangente hiperbólica também pertence às funções sigmoidais, e seu resultado diferentemente da função logística, assumi valores compreendidos entre - 1 e 1 , tendo sua expressão definida por:

$$
\phi\left(v_{k}\right)=\frac{1-\mathrm{e}^{-\beta . v_{k}}}{1+\mathrm{e}^{-\beta . v_{k}}}
$$

Figura 5. Função de ativação tangente hiperbólica.

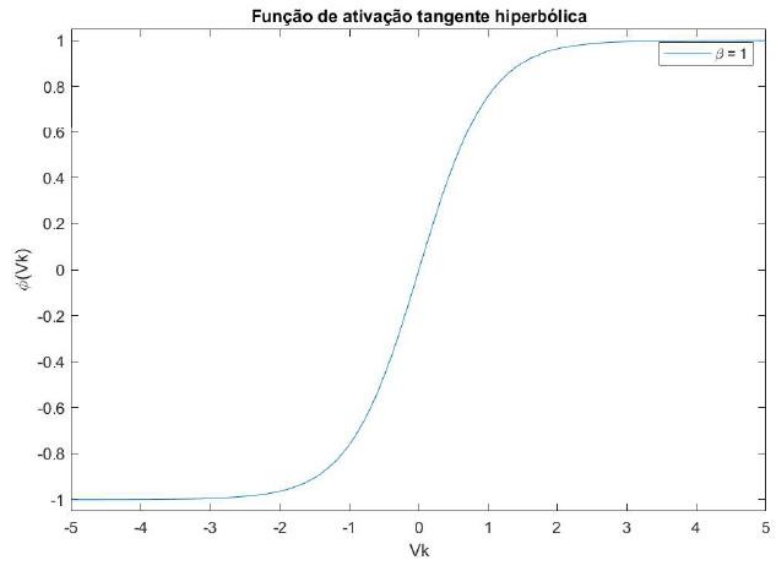

Fonte: (Autores, 2020).

c) Função linear: os resultados produzidos pela função linear, são idênticos aos valores do potencial de ativação $\left(v_{k}\right)$, conforme descrito em sua expressão matemática.

$$
\phi\left(v_{k}\right)=v_{k}
$$


Figura 6. Função de ativação linear.

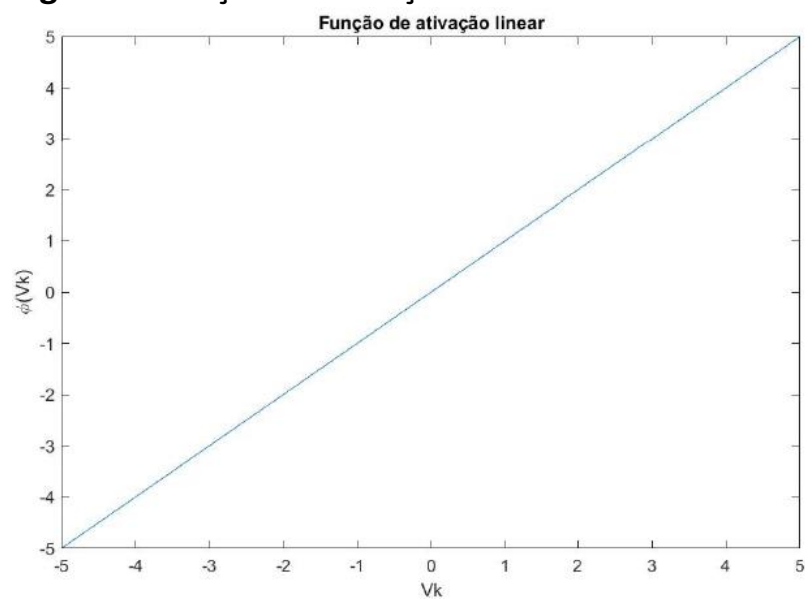

Fonte: Os autores.

\section{ARQUITETURAS DE RNA}

A arquitetura de uma rede neural artificial determina a forma em que os neurônios são arranjados nas camadas. A arquitetura RNA pode ser dividida em três partes, denominadas por camada de entrada, camada intermediária ou camada escondida e camada de saída. Vale ressaltar que o número de neurônios em cada camada pode ser diferente.

Dentre as principais arquiteturas, destacam-se as redes feedforward de camadas simples e as redes feedforward de camadas múltiplas.

Figura 7. Rede feedforward de camada múltiplas.

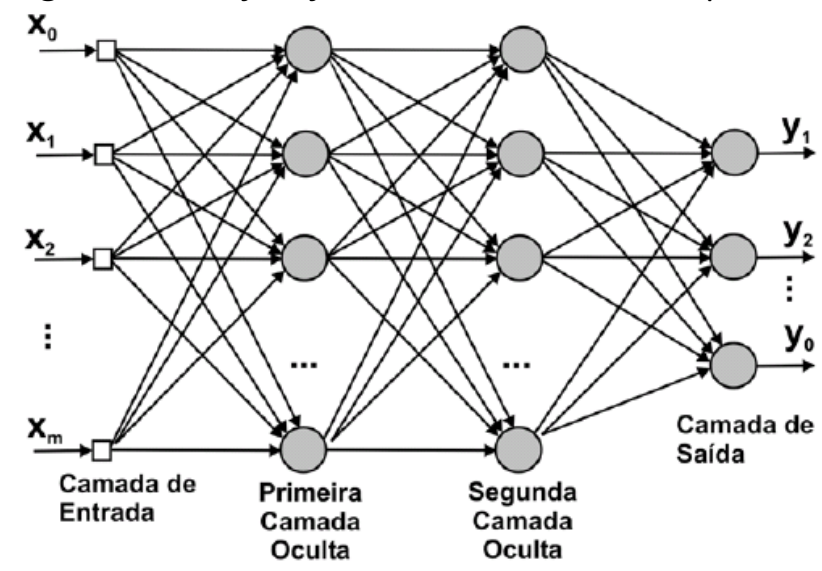

Fonte: (BARBOSA; FREITAS; NEVES, 2005).

Como visto na figura 7 , as redes feedforward de camadas múltiplas, possuem pelos menos uma camada escondida. São utilizadas em diversas aplicações, tais como classificação de padrões, identificação de sistemas, robótica, aproximação de funções etc. (SILVA; SPATTI; FLAUZINO, 2010).

\subsection{Perceptron de Múltiplas Camadas (Multiple Layer Perceptron)}

A rede Perceptron de Múltiplas Camadas

(PMC) é uma arquitetura feedforward de camadas múltiplas, e normalmente é utilizada para solução de problemas variantes no tempo, por exemplo, previsão de consumo de energia para os próximos meses. Uma topologia empregada nestes casos é a configuração TDNN (Time Delay Neural Network).

\subsubsection{Time Delay Neural Network (TDNN)}

Na rede TDNN é aplicado um atraso nas entradas, e a previsão dos valores futuros referente ao processo, é contado em função das entradas anteriores, como mostrado na seguinte expressão:

(6)

$$
x(t)=f\left(x(t-1), x(t-2), \ldots, x\left(t-n_{p}\right)\right)
$$

onde $n_{p}$ é a ordem do estimador, ou seja, o tamanho das amostras passadas que serão necessárias para estimação do valor atual de $x(t)$. Este modelo também é conhecido como Auto-Regressivo (AR).

Figura 8. Arquitetura PMC com entradas atrasadas no tempo.

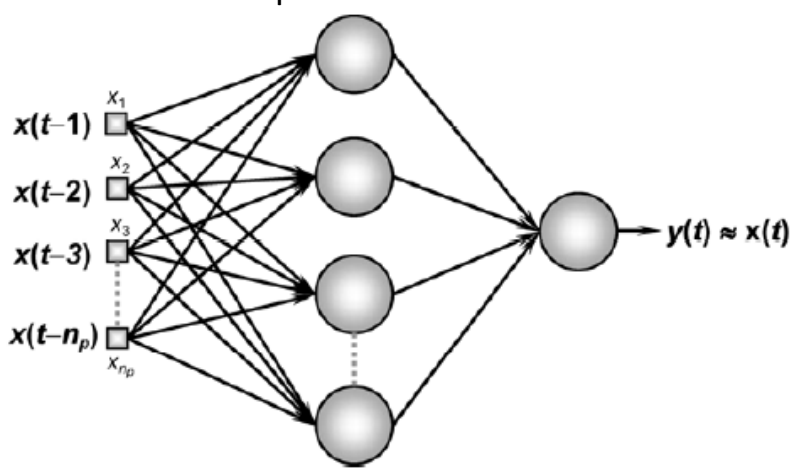

Fonte: (SILVA; SPATTI; FLAUZINO, 2010).

Essa linha de entrada atrasada no tempo funciona como memória, garantindo que amostras anteriores sejam sempre inseridas na rede.

O erro na saída é exemplificado por:

$$
E(t)=x(t)-y(t)
$$

e as iterações de tempo por

$$
\left(n_{p}+1\right) \leq t \leq N
$$

onde $N$ é a quantidade total de amostras.

Considere as seguintes entradas $x(t)=$ [ $\begin{array}{llllllllll}0,10 & 0,56 & 0,59 & 0,15 & 0,85 & 0,56 & 0,23 & 0,79 & 0,84\end{array}$ $0,23]$, sendo $N=10$.

Considere também uma ordem de predição igual a quatro, ou seja, a cada quatro 
amostras de entrada, uma saída é prevista, então

$n_{p}=4$ e $5 \leq t \leq 10$.

Tabela 1. Relação de entrada/saída.

\begin{tabular}{|c|c|c|c|c|c|}
\hline & $X(1)$ & $X(2)$ & $X(3)$ & $X(4)$ & $\begin{array}{c}\text { Saídas } \\
\text { esperadas }\end{array}$ \\
\hline $\mathrm{t}=5$ & $X(4)$ & $X(3)$ & $X(2)$ & $X(1)$ & $X(5)$ \\
\hline$t=6$ & $X(5)$ & $X(4)$ & $X(3)$ & $X(2)$ & $X(6)$ \\
\hline$t=7$ & $X(6)$ & $X(5)$ & $X(4)$ & $X(3)$ & $X(7)$ \\
\hline$t=8$ & $X(7)$ & $X(6)$ & $X(5)$ & $X(4)$ & $X(8)$ \\
\hline$t=9$ & $X(8)$ & $X(7)$ & $X(6)$ & $X(5)$ & $X(9)$ \\
\hline$t=10$ & $X(9)$ & $X(8)$ & $X(7)$ & $X(6)$ & $X(10)$ \\
\hline
\end{tabular}

Fonte: Os autores.

Tabela 2. Conjunto para treinamento.

\begin{tabular}{|c|c|c|c|c|c|}
\hline & $X(1)$ & $X(2)$ & $X(3)$ & $X(4)$ & $\begin{array}{c}\text { Saídas } \\
\text { esperadas }\end{array}$ \\
\hline$t=5$ & 0,15 & 0,59 & 0,56 & 0,1 & 0,85 \\
\hline$t=6$ & 0,85 & 0,15 & 0,59 & 0,56 & 0,56 \\
\hline$t=7$ & 0,56 & 0,85 & 0,15 & 0,59 & 0,23 \\
\hline$t=8$ & 0,23 & 0,56 & 0,85 & 0,15 & 0,79 \\
\hline$t=9$ & 0,79 & 0,23 & 0,56 & 0,85 & 0,84 \\
\hline$t=10$ & 0,84 & 0,79 & 0,23 & 0,56 & 0,23 \\
\hline
\end{tabular}

Fonte: Os autores.

Como visto nas tabelas 1 e 2, é possível observar uma operação de janela deslizante de largura $n_{p}$.

Tabela 3. Janela de deslocamento.

Fonte: Os autores.

\begin{tabular}{|l|l|l|l|l|l|l|l|l|}
\hline 0,1 & 0,56 & 0,59 & 0,15 & 0,85 & 0,56 & 0,23 & 0,79 & 0,84 \\
\hline 0,1 & 0,56 & 0,59 & 0,15 & 0,85 & 0,56 & 0,23 & 0,79 & 0,84 \\
\hline 0,1 & 0,56 & 0,59 & 0,15 & 0,85 & 0,56 & 0,23 & 0,79 & 0,84 \\
\hline 0,1 & 0,56 & 0,59 & 0,15 & 0,85 & 0,56 & 0,23 & 0,79 & 0,84 \\
\hline 0,1 & 0,56 & 0,59 & 0,15 & 0,85 & 0,56 & 0,23 & 0,79 & 0,84 \\
\hline
\end{tabular}

A janela deslizante é movimentada em uma unidade para a direta em cada instante de $t$, e assim a cada 4 entradas anteriores, uma saída é estimada.

\section{DISCUSSÃO E RESULTADOS}

Utilizando a arquitetura Perceptron de Múltiplas Camadas (PMC) e a topologia TDNN (Time Delay Neural Network), foi elaborado um algoritmo para a previsão de energia em um alimentador (circuito P4) da cidade de Presidente Prudente utilizando-se o software Matlab. Os dados são referentes à potência ativa consumida durante o mês de junho de 2020. 
Figura 9. Consumo de potência ativa em MWh durante o mês de junho em um alimentador de Presidente Prudente.

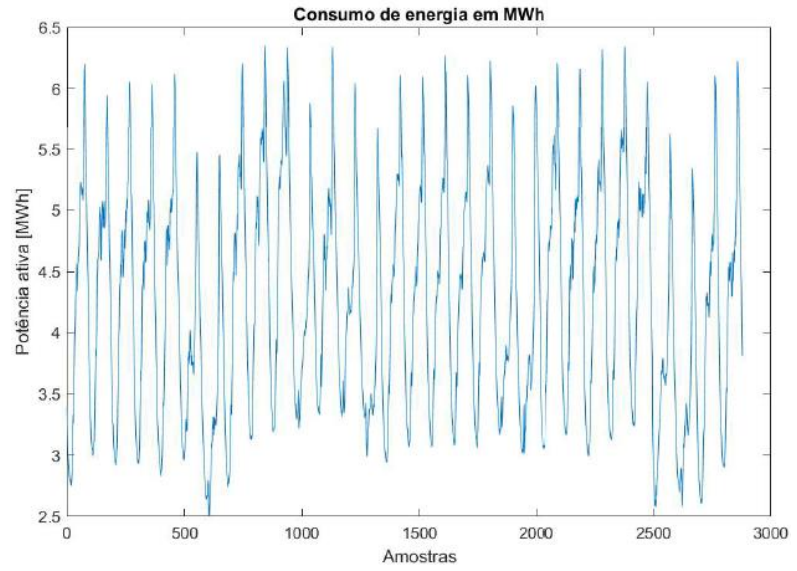

Fonte: Os autores.

O gráfico da figura 9 representa 0 consumo de potência ativa do alimentador com um intervalo de 15 minutos entre cada leitura. Reduzindo o gráfico para representar 24 horas, 0 mesmo descreve 96 pontos de leituras, como mostrado a seguir.

Figura 10. Consumo de potência ativa em $\mathrm{MWh}$ durante um dia de junho em um alimentado de presidente prudente.

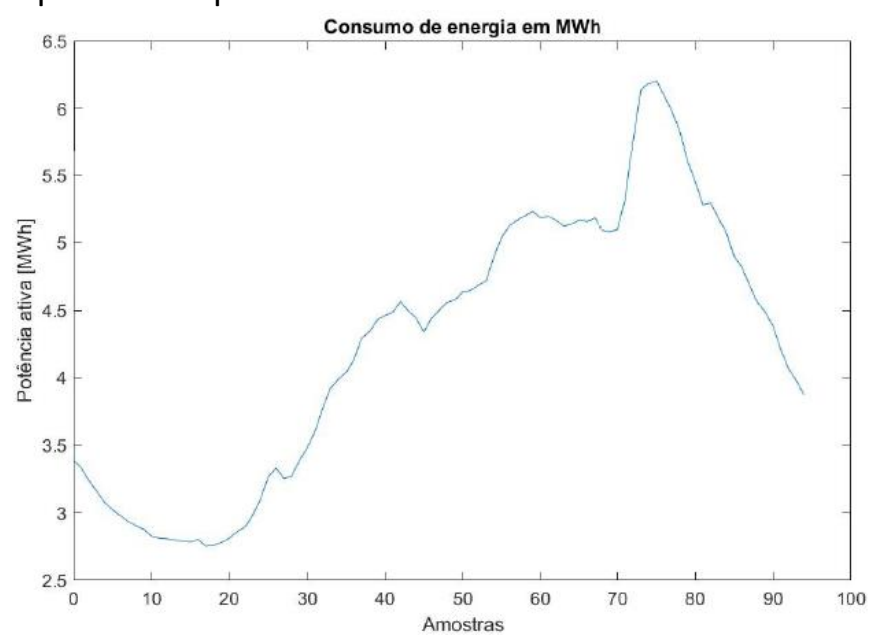

Fonte: Os autores.

Considerando este intervalo de um dia com 96 amostras, e executando o algoritmo TDNN com uma janela deslizante de tamanho 4, ou seja, $n_{p}=4$ e uma quantidade de 50 amostras anteriores $x(\mathrm{t})=50$, é possível realizar a previsão da próxima leitura $x(t)=51$.
Figura 11. Previsão da leitura $\boldsymbol{x}(\boldsymbol{t})=\mathbf{5 1}$ com uma janela de tamanho 4 e 50 amostras passadas. O círculo vermelho é a previsão do algoritmo.

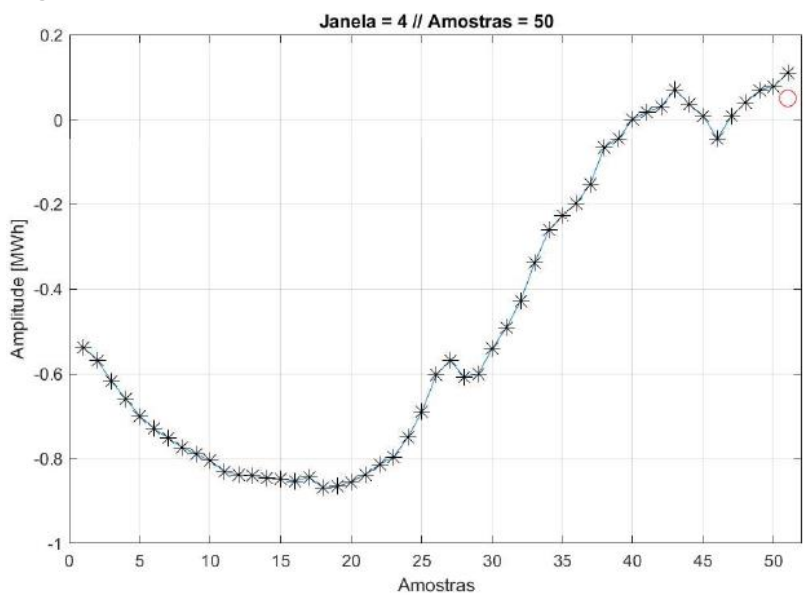

Fonte: Os autores.

Na figura 11 referente a previsão da amostra $x(t)=51$, é possível observar que há uma divergência do valor estimado e do valor real esperado. $O$ valor registrado é 4,638242 MWh enquanto o valor estimado encontrado é 2,119304 $M W h$ representando um erro de 2,518937 $M W h$. Em função do erro encontrado foi realizada uma segunda previsão aumentando-se o tamanho da janela. Para a segunda previsão utilizou-se uma janela de tamanho igual à 8 , ou seja, $n_{p}=8$.

Figura 12. Previsão da leitura $\boldsymbol{x}(\boldsymbol{t})=\mathbf{5 1}$ com uma janela de tamanho 8 e 50 amostras passadas. O círculo vermelho é a previsão do algoritmo.

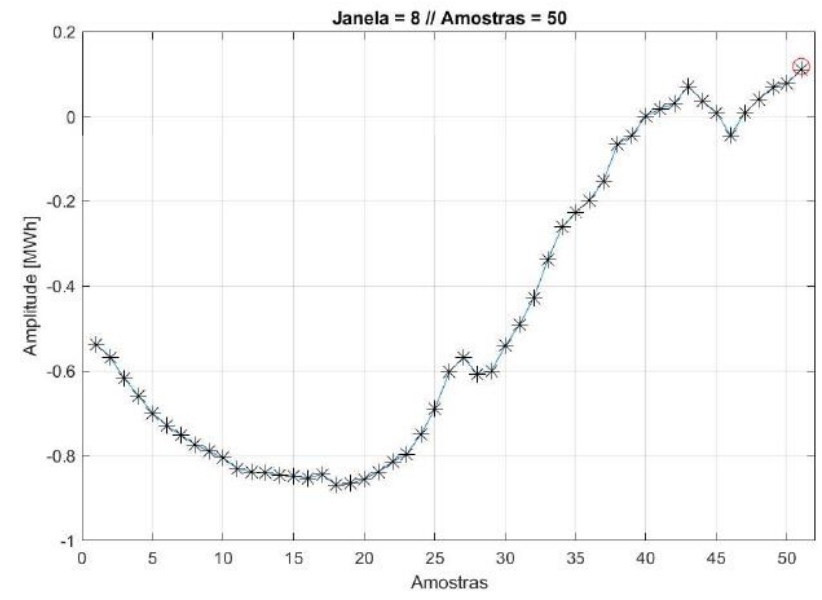

Fonte: Os autores.

Referente à última previsão, a estimação da amostra $x(t)=51$ com uma janela de tamanho 8 foi mais assertiva do que a janela de tamanha 4. Como já mencionado, o valor registrado é 4,638242 $M W h$ enquanto o valor 
estimado encontrado é 4,998460 $M W h$ representando um erro de $-0,360218 M W h$.

A fim de demonstrar o funcionamento do algoritmo, foi alterado a janela para um tamanho de 12 e separado um intervalo com 100 amostras, ou seja, o TDNN irá realizar a previsão para a amostra $x(t)=101$.

Figura 13. Previsão da leitura $\boldsymbol{x}(\boldsymbol{t})=101 \mathrm{com}$ uma janela de tamanho 12 e 100 amostras. O círculo vermelho é a previsão do algoritmo.

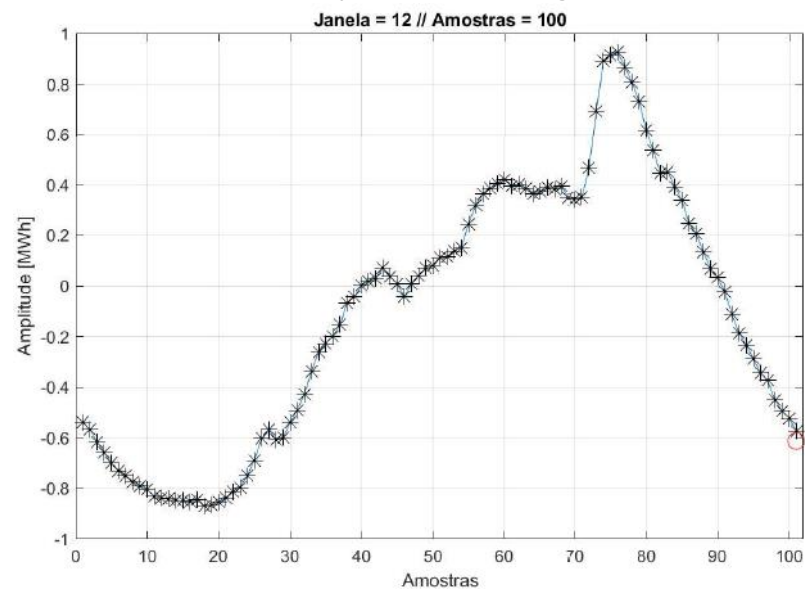

Fonte: Os autores.

O valor registrado para a amostra 101 é 3,322762 $M W h$ enquanto o valor estimado encontrado é 3,399631 $M W h$ representando um erro de $-0,076869 M W h$. Dessa forma, a TDNN implementada apresentou uma resposta satisfatória na previsão, como demonstrado no gráfico da figura 13.

\section{CONCLUSÕES}

O controle das operações do sistema elétrico seja na geração, transmissão e distribuição desempenha um papel fundamental para o bom funcionamento do sistema. Dessa forma, diversos recursos são implementados a fim de manter a segurança e manutenção do serviço de energia aos consumidores. Visando essa proposta, o presente trabalho, utiliza-se de uma rede neural artificial funcionando na arquitetura PMC com a topologia TDNN para previsão de potência ativa no alimentador P4 de Presidente Prudente. Verifica-se através da aplicação e ajustes da rede que são necessárias 100 amostras anteriores e uma janela de tamanho 12 para realizar uma previsão com um erro de $-0,076869 M W h$ entre o valor previsto pela rede e o valor medido pela concessionária local no barramento. Assim, tal proposta de rede neural para previsão de consumo de energia ativa demonstra-se promissora e poderá auxiliar, como recurso adicional, os centros de operação da distribuição na configuração de medidas protetivas antecipatórias a fim de garantir a segurança rede.

\section{AGRADECIMENTOS}

Ao grupo Energisa em Presidente Prudente, pelos dados fornecidos para realização desse estudo.

\section{REFERÊNCIAS}

ARANTES MONTEIRO, R. V. et al. Avaliação de algoritmos de treinamento de redes neurais artificiais para predição temporal de geração fotovoltaica. Energética, La Habana, v. 37, n. 3, p.. 218-228, dez. 2016. Disponível em http://scielo.sld.cu/scielo.php?script=sci_arttext \&pid=S1815$59012016000300007 \& \operatorname{lng}=e n \& n r m=i s o$. Acesso em: 20 ago. 2020.

BARBOSA, A. H.; FREITAS, M. S. R.; NEVES, F. .A. Confiabilidade estrutural utilizando o método de Monte Carlo e redes neurais. Rem: Rev. Esc. Minas, Ouro Preto, v. 58, n. 3, p. 247-255, Sept. $2005 . \quad$ Disponivel em: http://www.scielo.br/scielo.php?script=sci_arttex t\&pid=S0370-

$44672005000300011 \& \operatorname{lng}=e n \& n r m=$ iso. Acesso em: $\quad 16 \quad$ ago. 2020. https://doi.org/10.1590/S0370$\underline{44672005000300011 .}$

BEAR, Mark F.; CONNORS, Barry W.; PARADISO, Michael A. Neurociências: desvendando o sistema nervoso. Porto Alegre: Artmed, 2008.

$\mathrm{BERCl}$, C. D. Observadores Inteligentes de Estado: Propostas. 2008. Dissertação (Mestrado) - Universidade Estadual de Campinas, Campinas, $2008 . \quad$ Disponível em: http://repositorio.unicamp.br/jspui/handle/REPO SIP/258837. Acesso: 13 ago. 2020.

FERNANDES, J. O famoso potencial de ação. 2019. Jaleko, 2019. Disponível em: https://blog.jaleko.com.br/o-famoso-potencialde-acao/. Acesso: 13 ago. 2020.

FURTADO, H.; CAMPOS, V. H.; MACAU, E. Assimilação de dados com redes neurais artificiais em equações diferenciais. In: CONFERENCIA 
BRASILEIRA DE DINAMICA, CONTROLE E APLICAÇÃO. 10. 2011. Aguas de Lindória, SP. Anais [...]. Águas de Lindoia, 2011. Disponível em: $<$

https://www.researchgate.net/publication/2647 35169_ASSIMILACAO_DE_DADOS_COM_REDES_ NEURAIS_ARTIFICIAIS_EM_EQUACOES_DIFERENC IAIS>. Acesso: 13 agosto 2020.

MACHADO, W. C.; FONSECA JUNIOR, E. S.. Redes neurais artificiais aplicadas na previsão do VTEC no Brasil. Bol. Ciênc. Geod., Curitiba, v. 19, n. 2, p. 227-246, June 2013. Disponível em: http://www.scielo.br/scielo.php?script=sci_arttex t\&pid=S1982-

$21702013000200005 \& \operatorname{lng}=e n \& n r m=i s o>$. Acesso $\begin{array}{lll}\text { em: } & 20 & \text { ago.. }\end{array}$

https://doi.org/10.1590/S1982-

21702013000200005.

SILVA, I. N; SPATTI, D. H; FLAUZINO, R. A. Redes neurais artificiais para engenharia e ciências aplicadas: curso prático. 1.ed. São Paulo: Artliber, 2010.

SIQUEIRA-BATISTA, R. et al. As redes neurais artificiais e o ensino da medicina. Rev. bras. educ. med., Rio de Janeiro, v. 38, n. 4, p. 548-556, Dec. $2014 . \quad$ Disponivel em: http://www.scielo.br/scielo.php?script=sci_arttex $\mathrm{t} \& \mathrm{pid}=\mathrm{S} 0100$

$55022014000400017 \& \operatorname{lng}=e n \& n r m=i s o$. Acesso em: $20 \quad$ ago. 2020.

https://doi.org/10.1590/S0100$\underline{5022014000400017 .}$. 